\title{
A termite symbiotic mushroom maximizing sexual activity at growing tips of vegetative hyphae
}

\author{
Huei-Mei Hsieh', Mei-Chu Chung ${ }^{1}$, Pao-Yang Chen', Fei-Man Hsu', Wen-Wei Liao', Ai-Ning Sung', \\ Chun-Ru Lin' ${ }^{1}$, Chung-Ju Rachel Wang ${ }^{1}$, Yu-Hsin Kao ${ }^{1}$, Mei-Jane Fang ${ }^{1}$, Chi-Yung Lai ${ }^{2}$, Chieh-Chen Huang ${ }^{3}$, \\ Jyh-Ching Chou ${ }^{4}$, Wen-Neng Chou ${ }^{5}$, Bill Chia-Han Chang ${ }^{6}$ and Yu-Ming Ju ${ }^{{ }^{*}}$
}

\begin{abstract}
Background: Termitomyces mushrooms are mutualistically associated with fungus-growing termites, which are widely considered to cultivate a monogenotypic Termitomyces symbiont within a colony. Termitomyces cultures isolated directly from termite colonies are heterokaryotic, likely through mating between compatible homokaryons.

Results: After pairing homokaryons carrying different haplotypes at marker gene loci MIP and RCB from a Termitomyces fruiting body associated with Odontotermes formosanus, we observed nuclear fusion and division, which greatly resembled meiosis, during each hyphal cell division and conidial formation in the resulting heterokaryons. Surprisingly, nuclei in homokaryons also behaved similarly. To confirm if meiotic-like recombination occurred within mycelia, we constructed whole-genome sequencing libraries from mycelia of two homokaryons and a heterokaryon resulting from mating of the two homokaryons. Obtained reads were aligned to the reference genome of Termitomyces sp. J132 for haplotype reconstruction. After removal of the recombinant haplotypes shared between the heterokaryon and either homokaryons, we inferred that 5.04\% of the haplotypes from the heterokaryon were the recombinants resulting from homologous recombination distributed genome-wide. With RNA transcripts of four meiosis-specific genes, including SPO11, DMC1, MSH4, and MLH1, detected from a mycelial sample by real-time quantitative PCR, the nuclear behavior in mycelia was reconfirmed meiotic-like.

Conclusion: Unlike other basidiomycetes where sex is largely restricted to basidia, Termitomyces maximizes sexuality at somatic stage, resulting in an ever-changing genotype composed of a myriad of coexisting heterogeneous nuclei in a heterokaryon. Somatic meiotic-like recombination may endow Termitomyces with agility to cope with termite consumption by maximized genetic variability.
\end{abstract}

Keywords: Symbiosis, Odontotermes formosanus, Termitomyces mushroom, Meiotic-like, Basidiomycota

\section{Background}

Fungus-growing termites (Macrotermitinae, Isoptera) have practiced farming with their fungal symbionts of the basidiomycete genus Termitomyces R. Heim (Lyophyllaceae, Agaricales) as the cultivars since ca. 24-34 million years ago in the African rainforest (Aanen and

\footnotetext{
${ }^{*}$ Correspondence: yumingju@gate.sinica.edu.tw

1 Institute of Plant and Microbial Biology, Academia Sinica,

Taipei 11529, Taiwan

Full list of author information is available at the end of the article
}

Eggleton 2005; Roberts et al. 2016). Decomposing activity on plant matters of Termitomyces symbionts appears complemented by that of termite gut microbiota, which was suggested by analyzing annotated draft genomes from Macrotermes natalensis (Haviland) and its Termitomyces symbiont along with gut metagenomes from individuals of various termite castes (Poulsen et al. 2014). Fungus-growing termites, much as leaf-cutting ants, cultivate only one fungal symbiont in a colony (Aanen et al. 2009; Katoh et al. 2002; Mueller et al. 2005; Shinzato et al. 2005), which is widely accepted as a genotypic 
monoculture involving only one genotype of a particular Termitomyces species. This is in sharp contrast to genotypic polycultures and species polycultures, which are commonly adopted in human agriculture and have widely been perceived as better farming practices than monocultures, because diverse systems can be more productive, stable, and resistant to invasions than less diverse systems (Cook-Patton et al. 2011).

A Termitomyces mushroom (Fig. 1a-c) is cultivated by the only macrotermitine species known in Taiwan, black-winged subterranean termite Odontotermes formosanus Shiraki (Fig. 1e), at fungus gardens (Fig. 1c, d), which are built underground with fecal balls excreted by termite workers. Two types of spores are produced by the Termitomyces mushroom: while conidia are produced at fungus gardens, ingested by termite workers, and repeatedly mixed within fecal balls, basidiospores are only found on the gill surface of fruiting bodies, which emerge above-ground from fungus gardens in summer. Mutualistic relationship between O. formosanus and its Termitomyces symbiont can be demonstrated by rearing of O. formosanus in laboratory, which only becomes sustainable with incipient termite colonies artificially inoculated with spores of the symbiont (Fig. 1d). Associations between African macrotermitine termites and Termitomyces mushrooms have previously been established by artificially inoculating incipient termite colonies with Termitomyces spores (Johnson 1981; Johnson et al. 1981; Sands 1960).

A typical life cycle in the majority of basidiomycetes has a prolonged heterokaryotic (often dikaryotic) somatic stage, usually containing two genetically heterogeneous nuclei resulting from fusion of compatible homokaryons (Fig. 2a-f), which is governed by a self-incompatible mating system (Anderson and Kohn 2007; Brown and Casselton 2001; Raper 1966; Raudaskoski and Kothe 2010). Nuclei of heterokaryons stay unfused within every cell until formation of basidia at fruiting bodies, where the nuclei undergo fusion and meiosis (Brown and Casselton 2001). Four basidiospores are normally produced on the top of a basidium, each receiving a nucleus resulting from meiosis. A potentially great genetic variability thus exists among basidiospores, i.e., because they are products of meiosis, where genome-wide recombination can give rise to a great amount of genetic diversity in the offspring.

Here we show that the Termitomyces symbiont of $O$. formosanus possesses a life cycle different from other basidiomycetes in having a somatic sexual process involving karyogamy and meiotic-like nuclear division during cell division at active hyphal tips (Fig. $2 \mathrm{~g}-\mathrm{m}$ ). The sexual process empowers its growing mycelium a hyperdynamic genotype composed of a myriad of nuclear haplotypes and renders the symbiont with immense genetic variability. The sexual process was confirmed by cytological studies, whole-genome sequencing, and real-time quantitative PCR of four meiosis-specific genes. Pairing tests indicated that mating system of the Termitomyces symbiont may not be governed by heterogenic compatibility as in the typical life cycle found in heterothallic basidiomycetes (Fig. 2a-f).

\section{Methods}

\section{Fungal isolations}

Termitomyces cultures were isolated from a fruiting body T0984 collected from Nan-tou County, Taiwan, in 2009. The termite colony was not excavated to confirm its connection with T0984. However, by inoculating the conidia produced in culture by T0984 into colonies of O. formosanus (see below), we were able to confirm the symbiotic relationship between the two partners. Two types of fungal cultures were obtained or derived from this fruiting body: a heterokaryon $(F B)$ and homokaryons $(B S) . F B$ was isolated directly from the stipe tissue and served as the inoculum for laboratory-reared termite colonies, from which the fungus was reisolated by obtaining single conidia from guts of worker termites from the colonies and was confirmed to be $F B$. The $F B$ culture was originally obtained by paring away the stipe surface with a heated razor blade, removing a piece of the stipe tissue from underneath by sterilized forceps, and placing the removed tissue on 2\% Difco malt extract agar (MEA, 20 g/L Difco malt extract, 20 g/L Difco agar). Emerging hyphal tips were excised and transferred to fresh MEA. $B S$ cultures were obtained from single basidiospores and were used for pairing tests. Those $B S$ cultures were initiated from spreading onto MEA a large number of basidiospores, which were collected by placing the pileus of T0984 on a sterilized plate for several hours, allowing basidiospores to fall from gills. Germination rates of the Termitomyces basidiospores were extremely low, and only one out of several hundred started to germinate after 2 days. A fine glass needle was used to gently guide germinating basidiospores bearing a short germ tube to clean areas on the agar, where agar blocks each overlain with a germinating basidiospore were excised and transferred to fresh MEA. We eventually obtained 43 BS isolates, whose growth rates varied greatly, $1-4 \mathrm{~cm}$ diam/ month. Twenty of the $B S$ cultures, i.e., $B S O 2, B S 03, B S 04$, BS05, BS06, BS09, BS10, BS11, BS14, BS17, BS18, BS19, BS21, BS26, BS27, BS31, BS32, BS35, BS38, and BS39, were randomly selected for subsequent pairing tests.

\section{Termite rearing and fungal inoculation}

To test if the Termitomyces culture $(F B)$ that we isolated from the fruiting body T0984 was indeed a symbiont of O. formosanus, laboratory-reared colonies of the termite 

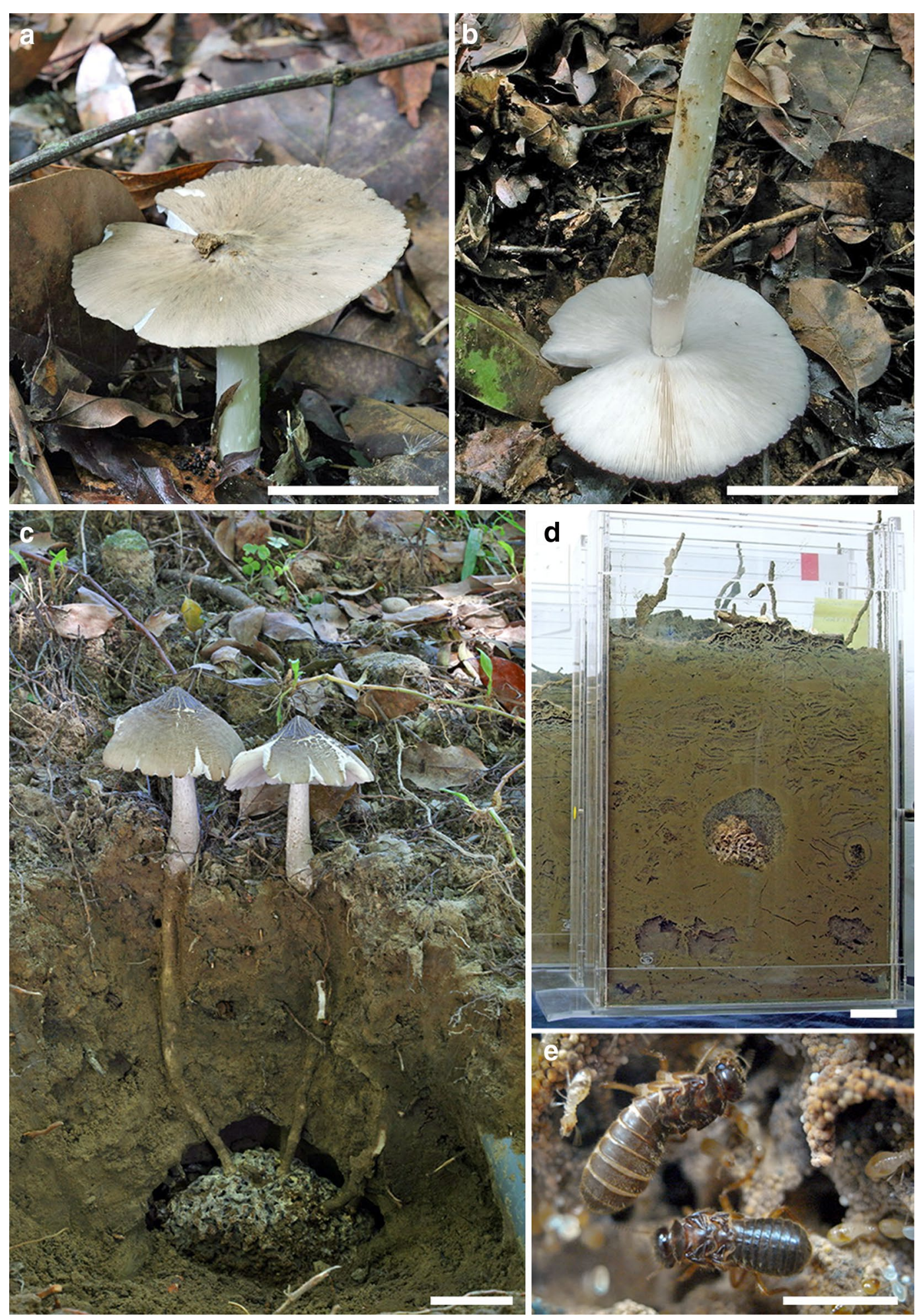

Fig. 1 Termitomyces mushroom and Odontotermes formosanus. a Surface of the pileus showing a central umbo. b Underside of the pileus showing white gills and a centrally attached stipe. c Soil profile to show the fruiting bodies emerging from a subterranean fungus garden. d Laboratoryreared termite colony at 3.5 years with a fungus garden ca. $7 \mathrm{~cm}$ diam. e Queen (upper) and king (lower) on the fungus garden shown in $\mathbf{d}$. Scale bars in $\mathbf{a}-\mathbf{d}=5 \mathrm{~cm}$, and $\mathbf{e}=0.5 \mathrm{~cm}$. a, b From the fruiting body T0984; $\mathbf{c}$ From National Museum of Natural Science, Taichung, Taiwan; and d, e from a termite colony inoculated with T0984 


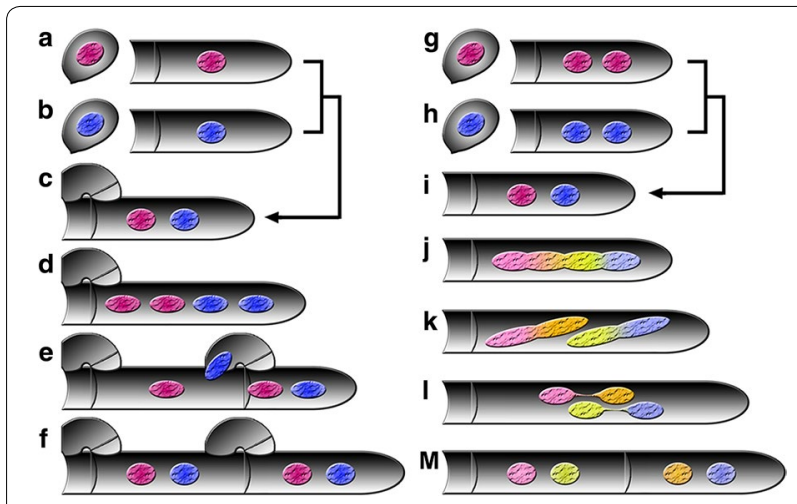

Fig. 2 Diagrammatic representation to contrast somatic growths between basidiomycetes with a typical life cycle and the Termitomyces symbiont. a-f Various stages of hyphal growth in a typical basidiomycete, whose heterokaryons (usually dikaryons), unlike those of Termitomyces, have a clamp connection at hyphal septa and dikaryotic mycelia, two commonly used indicators for successful

matings. a, b Uninucleate homokaryons carrying different markers (red and blue) from single uninucleate basidiospores. c Binucleate heterokaryon resulting from pairing of two homokaryons. $\mathbf{d}$ Mitosis giving rise to four nuclei. e Formation of clamp connection, through which a blue nucleus migrates back to the penultimate cell, while two new septa are formed in the clamp cell and hyphal tip. $\mathbf{f}$ The final stage of hyphal cell division. $\mathbf{g}$-m Various stages of Termitomyces hyphal growth. Note that a growing hyphal cell of a homokaryon or heterokaryon is binucleate or trinucleate. Only binucleate tip cells are shown here. $\mathbf{g}$, $\mathbf{h}$ Binucleate homokaryons carrying different markers (red and blue) from single uninucleate basidiospores. i Binucleate heterokaryon resulting from pairing of two homokaryons. Homokaryons and heterokaryons cannot be discerned by nuclear numbers, both having two or three nuclei in a growing hyphal cell. $\mathbf{j}$ Karyogamy. $\mathbf{k}$ Stage resembling Meiosis I. I Stage resembling Meiosis II. $\mathbf{m}$ Two cells separated by a newly formed septum as the final stage

were initiated from alates captured during nuptial flight on the campus of Academia Sinica, Taiwan in June, 2009. Six dealates were placed in each 9-cm plastic Petri dish containing wet sifted soil to ensure the presence of both sexes. A chamber was created by the dealates at bottom of the soil within a few hours. Eggs were laid in 10 days. After the first brood of workers matured and emerged for foraging ca. 2.5 months after the nuptial flight, conidial suspension (ca. $10^{5}$ conidia/mL) prepared from the culture $F B$ (Table 1) was inoculated into 34 termite colonies, in which 21 formed fungus gardens within several days. They were survived by eight termite colonies after 6 years. The colonies were reared mainly with autoclaved twigs of Norfolk Island pine Araucaria heterophylla (Salisb.) Franco.

\section{DNA extraction, PCR, cloning, and sequencing}

All of the cultures that we used in this study were subjected to sequencing of their nuclear ribosomal internal transcribed spacers (ITS), mitochondrial intermediate peptidase $(M I P)$, and pheromone receptor protein homologue $(R C B)$. Mycelia were grown in $100 \mathrm{~mL}$ of malt extract broth (20 g/L Difco malt extract) on a rotary shaker at $120 \mathrm{rpm}$ for $6-8$ weeks. They were harvested by filtration through Whatman No. 1 filter papers, freezedried, and stored at $-20{ }^{\circ} \mathrm{C}$. Total DNA from a dried fungal mycelium was extracted by using a SLA-32 automatic nucleic acid extractor (Taiwan Advanced Nanotech Inc.) with a TANBead ${ }^{\circledR}$ Fungi DNA extraction kit. The three nuclear DNA loci, ITS, MIP, and $R C B$ were amplified with the primer pairs ITS1/ITS4 (White et al. 1990), $M A F / M A R$, and $M R 8 F / M R 8 R$, respectively, via polymerase chain reaction (PCR) in 96-well GeneAmpt ${ }^{\circledR}$ PCR System 9700 (Applied Biosystems, Foster City, California, USA) and sequenced with ABI Big-dye primer sequencing kit (Applied Biosystems). The primer pair and PCR condition of ITS followed the cited reference (White et al. 1990). See below for the primer pairs and the PCR condition of $M I P$ and $R C B$. The resulting sequencing reactions were electrophoresed on an ABI 3730xl DNA sequencer. PCR products were cleaned with PCR-M ${ }^{\mathrm{TM}}$ clean-up system (Viogene-Biotek Corp., Hsi-chih, New Taipei City, Taiwan) following the manufacturer's protocol. While PCR products of homokaryons were sequenced directly, those of heterokaryons were subjected to cloning process using $\mathrm{pGEM}^{\circledR}$-T vector System I (Promega, Madison, Wisconsin, USA) or Zero Blunt TOP10 plasmid vector (Invitrogen Inc., Carlsbad, California, USA). The plasmids were extracted with plasmid DNA extraction kit Mini Plus $^{\text {TM }}$ (Viogene-Biotek Corp.). Multiple clones of a PCR product were sequenced.

The PCR condition was the same for $M I P$ and $R C B$ : ca. $100 \mathrm{ng}$ template DNA, $1.0 \mathrm{mM} \mathrm{MgCl}_{2}, 0.2 \mathrm{mM}$ each dNTP, $0.2 \mu \mathrm{M}$ each primer, and 1.25 U Easy-A HighFidelity PCR Cloning Enzyme (Agilent Technologies, Santa Clara, California, USA) in a $25 \mu \mathrm{L}$ reaction. Thermal cycling parameters were: an initial denaturation step at $95{ }^{\circ} \mathrm{C}$ for 2 min followed by 30 cycles of denaturing at $95{ }^{\circ} \mathrm{C}$ for $40 \mathrm{~s}$, annealing at $57{ }^{\circ} \mathrm{C}$ for $30 \mathrm{~s}$, extension at $72{ }^{\circ} \mathrm{C}$ for $1 \mathrm{~min}$, and a $7 \mathrm{~min}$ final extension at $72{ }^{\circ} \mathrm{C}$. The MIP locus used in the current study was a shorter version of that published in (James et al. 2004). The primer pair MAF/MAR (5'-AATGTGTCTGGTACCCGTTGTCCC$3^{\prime} / 5^{\prime}$-ATGTCCAAACTGGGTCTGGAAAGAT-3') was designed to frame a 327 bp fragment, where 13 SNP sites were available. The $R C B$ locus was amplified with the primer pair $M R 8 F / M R 8 R$ (5' - AACCTGCATACCCTCTCTTCCCTAT-3'/5' GTAATCCAACGGAAGCACCAAGCAT- $3^{\prime}$ ), which framed a 289 bp fragment with seven SNP sites available. The reverse primer $M R 8 R$ was located within $R C B 1$ (Aimi et al. 2005), whereas the forward primer $M R 8 F$ was located at a $5^{\prime}$-untranslated region, which 
Table 1 Heterokaryons resulting from pairings between 20 homokaryons, which were sorted into four genotypes, i.e., $A_{1} B_{1}, A_{2} B_{2}, A_{1} B_{2}$, and $A_{2} B_{1}$, by haplotypes at $M I P$ and $R C B$

\begin{tabular}{|c|c|c|c|c|}
\hline & $A_{1} B_{1} \times A_{2} B_{2}$ & $A_{1} B_{2} \times A_{2} B_{1}$ & $A_{2} B_{2} \times A_{2} B_{1}($ common at $A)$ & $A_{1} B_{2} \times A_{2} B_{2}($ common at $B)$ \\
\hline $\begin{array}{l}\text { Mating } \\
\text { pairs }\end{array}$ & $\begin{array}{l}B S 11 \times B S 09, B S 11 \times B S 32 \\
B S 18 \times B S 09, B S 18 \times B S 27 \\
B S 18 \times B S 32, B S 39 \times B S 09 \\
B S 39 \times B S 32\end{array}$ & $\begin{array}{l}B S O 2 \times B S O 3, B S 17 \times B S 03 \\
B S 17 \times B S 05, B S 17 \times B S 10\end{array}$ & $\begin{array}{l}B S 04 \times B S 31, B S 06 \times B S 35 \\
\quad B S 09 \times B S 31\end{array}$ & $\begin{array}{l}B S 14 \times B S 19, B S 14 \times B S 38, B S 21 \times B S 19, \\
B S 21 \times B S 32, B S 21 \times B S 38, \\
B S 26 \times B S 19, B S 26 \times B S 32 \\
B S 26 \times B S 38\end{array}$ \\
\hline $\operatorname{MIP}(A)$ & + & + & ND & + \\
\hline$R C B(B)$ & + & + & + & ND \\
\hline
\end{tabular}

For each of the four pairing groups, we randomly selected three homokaryons of a genotype to pair with three homokaryons of another genotype. Note that there were nine mating pairs within each pairing group, but only confirmed heterokaryons are listed

+ Both haplotypes detected, ND not determined because of identical haplotype

was reached by chromosome walking from $R C B 1$. The chromosome walking was done with TaKaRa LA PCR InVitro Cloning Kit (TaKaRa Bio Inc., Otsu, Shiga, Japan). Template DNAs were prepared according to the manufacturer's instructions and were subjected to digestion with SalI. The digested DNA fragments were then ligated with nucleotide linkers and used as templates for two rounds of cassette amplification by PCR, which was conducted with two primer pairs SU1 (5'-GCATCGT TTGCCCAGACGACAGAA-3')/SU2 (5'-ACGCCATGTAGAAACAAGTTCCTG-3') and SU71 (5'-GCGTCGTTCGCCCAGACGACAGAA-3')/SU7-2 (5'-ACGTCATGTAGAAACAAGTTCCTG-3'). After cassette amplification, all amplified DNA fragments were purified, cloned, and sequenced.

\section{DNA marker loci for pairings and pairing tests}

$M I P$ and $R C B$ were used as marker loci to confirm whether or not a pairing was successful, because Termitomyces species lack phenotypic markers. In other basidiomycetes, $M I P$ is closely linked to mating locus $A$ (James et al. 2004), whereas $R C B$ is located within mating locus $B$ (Aimi et al. 2005).

Pairings of the 20 homokaryotic $B S$ cultures were conducted for pairs carrying different haplotypes at both $M I P$ and $R C B\left(A_{1} B_{1} \times A_{2} B_{2}\right.$ and $\left.A_{1} B_{2} \times A_{2} B_{1}\right)$, at $M I P$ only $\left(A_{1} B_{2} \times A_{2} B_{2}\right.$, i.e., common-B), and at $R C B$ only $\left(A_{2} B_{2} \times A_{2} B_{1}\right.$, i.e., common-A). Genotypes of the 20 homokaryons were determined and sorted into $A_{1} B_{1}$, $A_{2} B_{2}, A_{1} B_{2}$, and $A_{2} B_{1}$. For each of the four pairing groups shown in Table 1 , we randomly selected three homokaryons of a genotype to pair with three homokaryons of another genotype, i.e., nine pairs in each pairing group. Homokaryons of a pair were placed $1 \mathrm{~cm}$ apart on a 6-cm petri plate containing MEA. Agar blocks containing hyphae at the confrontation line were isolated after 1 month for molecular typing. For homokaryons of those pairs with different haplotypes at both $M I P$ and $R C B$, successful matings would result in heterokaryons within which both haplotypes of $M I P$ and both of $R C B$ coexist. In those cases where paired homokaryons carrying different haplotypes at only one of the two loci, resulting heterokaryons would be expected to carry either both haplotypes of $M I P$ or both of $R C B$.

\section{Nuclear staining}

Nuclei of basidiospores, hyphae, and conidia were stained directly with DAPI $\left(4^{\prime}, 6\right.$-diamidino-2-phenylindole in an antifade solution, Vector Laboratories, California, USA). Basidiospores were collected from the fruiting body T0984. Hyphae and conidia were obtained from culturing mycelia of $F B, B S \mathrm{~s}$, and paired $B S \mathrm{~s}$ (Table 1) in $250 \mathrm{~mL}$ Erlenmeyer flasks, each of which contained a $100 \mathrm{~mL}$ liquid medium consisting of $3 \mathrm{~g} / \mathrm{L}$ Bacto beef extract, $5 \mathrm{~g} / \mathrm{L}$ Bacto peptone, and $15 \mathrm{~g} / \mathrm{L}$ D-glucose, and incubated without shaking at $25{ }^{\circ} \mathrm{C}$ for 3 week. The stained fungal components were examined by fluorescence microscopy with a Zeiss LSM510 Meta confocal microscope equipped with C-Apochromat $63 \times / 1.2 \mathrm{~W}$ corr objective. Two channels were used: DAPI channel (specifications: Two Photo Laser Excitation: 740 nm; Transmission 1.5\%; Main Beam Splitter: KP650; Beam Splitter 2: mirror; BP 390415IR; Detector Gain: 650; Amplifier Offset: -0.1) and DIC channel (specifications: Two Photo Laser Excitation: 740 nm; Detector Gain: 130; Amplifier Offset: -0.1).

Hyphae and conidia were also subjected to $\mathrm{HCl}$ Giemsa stains (Giemsa's azur eosin methylene blue solution, Merck KGaA, Darmstadt, Germany) in accordance with published protocols (Knox-Davies and Dickson 1960; Ward and Ciurysek 1962) with slight modification and is summarized as follows. A harvested mycelium was washed with MQ water, fixed in a freshly prepared Farmer's fluid (95\% ethanol: glacial acetic acid = 3:1) for $1 \mathrm{~h}$, and successively washed in 95 and 70\% ethanol, and immersed in MQ water for $10 \mathrm{~min}$. It was then placed in $1 \mathrm{~N} \mathrm{HCl}$ at room temperature for $10 \mathrm{~min}$, hydrolyzed in $1 \mathrm{~N} \mathrm{HCl}$ at $60{ }^{\circ} \mathrm{C}$ for $8 \mathrm{~min}$, washed in MQ water with 5 changes, suspended in phosphate buffer $\left(0.2 \% \mathrm{KH}_{2} \mathrm{PO}_{4}\right.$, 
$0.4 \% \mathrm{Na}_{2} \mathrm{HPO}_{4} \cdot 7 \mathrm{H}_{2} \mathrm{O}, \mathrm{pH}$ 7.2) for $5 \mathrm{~min}$, and stained in $\mathrm{HCl}-$ Giemsa for $15 \mathrm{~min}$ or longer if required. The stained mycelium was washed thoroughly with MQ water and phosphate buffer in series, and was mounted in MQ water. The stained fungal components were examined by light microscopy with a Leica DMRB microscope equipped with a PL Fluotar $100 \times / 1.30$ oil objective.

Slide culture technique was also used with small blocks (ca. $0.5 \times 0.5 \mathrm{~cm})$ of Difco oatmeal agar (OA) (BD, Sparks, Maryland, USA), each of which was inoculated with a culture, sandwiched between a cover slip and a microscope slide, and grown for 2 week. The hyphal mats and conidia that attached on the cover slip were then stained with DAPI and HCl-Giemsa as described above.

\section{Fluorescence in situ hybridization (FISH)}

Hyphae from cultures of the heterokaryon $B S 05 \times B S 17$ and the homokaryon $B S 05$ were harvested and fixed in freshly prepared Farmer's fluid overnight. Hyphae were submerged within a drop of $45 \%$ acetic acid while being evenly spread onto a microscope slide prior to air-dried. Cell wall digestion was performed with $100 \mathrm{mg} / \mathrm{mL}$ lysing enzyme from Trichoderma harzianum (Sigma-Aldrich, St. Louis, Missouri, USA) dissolved in PME $(50 \mathrm{mM}$ PIPES, pH 6.7; 25 mM EGTA, $\mathrm{pH} 8 ; 5 \mathrm{mM} \mathrm{MgSO}_{4}$ ) for $2 \mathrm{~h}$ at $37^{\circ} \mathrm{C}$. Probe DNA was prepared with the ITS1$5.8 S$ rDNA-ITS2 sequence of the $F B$ culture amplified and labelled with digoxigenin-11-dUTP by using PCR DIG Labelling Mix (Roche Diagnostics GmbH, Penzberg, Germany). The PCR condition is as described above for ITS. The FISH procedure (Chung et al. 2008) is briefly described as follows. The nuclei on the microscope slide were denatured in $70 \%$ deionized formamide in $2 \times$ SSC $(0.15 \mathrm{M} \mathrm{NaCl}, 0.015 \mathrm{M}$ sodium citrate, $\mathrm{pH} 7.5)$ at $80{ }^{\circ} \mathrm{C}$ for $60 \mathrm{~s}$. Hybridization mixture was prepared from $50 \%$ deionized formamide, $2 \times$ SSC, sheared salmon sperm DNA $(1 \mu \mathrm{g} / \mu \mathrm{L}), 10 \%$ dextran sulfate, and probe DNA (10-100 ng in $20 \mu \mathrm{L}$ per microscope slide). Hybridization was performed in a moisture chamber at $37^{\circ} \mathrm{C}$ overnight. Hybridization signals were visualized using a rhodamineconjugated anti-digoxigenin antibody (Roche Diagnostics $\mathrm{GmbH}$ ). The nuclei were counterstained with DAPI.

For a fungal culture, FISH preparations were conducted for more than ten times, from each of which eight microscope slides were resulted. More than 20 images of a nuclear stage, i.e., prophase, metaphase, anaphase, or telophase, with clear FISH signals were taken from each FISH preparation.

\section{PCR-free library construction and high throughput sequencing}

Genomic DNAs were extracted from dried mycelia of two homokaryons (BSO5 and BS17) and a heterokaryon
$($ BSO5 $\times$ BS17) by using a SLA-32 automatic nucleic acid extractor with a TANBead ${ }^{\circledR}$ Fungi DNA extraction kit. Approximately $1 \mu \mathrm{g}$ of a genomic DNA was sonicated to 350 bp with the Covaris M220 system using the following parameters: duty factor $20 \%$, peak/display power $50 \mathrm{~W}, 200$ cycles per burst, $65 \mathrm{~s}, 20{ }^{\circ} \mathrm{C}$. The sonicated DNA was purified, end-repaired, A-tailed and ligated with adaptors according to the manufacture's guide (Illumina Truseq DNA PCR-Free LT library prep kit) followed by purification and sequencing. A paired-end DNA-seq library was sequenced using Illumina HiSeq 2500 platform per manufacturer's instructions. Sequencing was performed up to 250 cycles. Image analysis and base calling were performed with the standard Illumina pipeline. In total $17,621,957,23,362,228$, and $18,348,369$ reads were aligned to the reference genome Termitomyces sp. $J 132$ (Poulsen et al. 2014), with the estimated depths of $32.3 \times, 42.8 \times$, and $33.6 \times$ for $B S 05 \times B S 17, B S 05$, and $B S 17$, respectively.

\section{Alignments, heterozygous SNP calling, detection of recombinants, and haplotype inference}

After the adapter trimming by cutadapt 1.8.1 (Martin 2011), the reads were aligned to the reference genome of Termitomyces sp. J132 (Poulsen et al. 2014), downloaded from http://gigadb.org/dataset/100056, by using Bowtie 2 with local alignment mode to optimize the mapability (Langmead and Salzberg 2012). Alignments of the homokaryon and heterokaryon samples are publicly available at NCBI as Study SRP073090.

To identify potential recombinants, we first searched for heterozygous SNPs with two alleles, as a proxy to the parental alleles. During the SNP calling, the alignments with low mapping quality (MAPQ score $<10$ ) were skipped. A heterozygous SNP was identified when the following conditions were met: the depth was $\geq 10$ reads, the two major alleles accounted for $\geq 90 \%$ of the reads, and the difference between them was $\leq 20 \%$. In total we found $71.5,60.9$, and $74.7 \mathrm{~K}$ heterozygous SNPs in $B S 05 \times B S 17, B S 05$, and $B S 17$, respectively. Due to the high variability of fungus genomes, a large number of the SNPs were likely due to the genetic difference between our strains and the reference strain. We further filtered out the SNPs from the heterokaryon that were also detected in either of the two homokaryons.

Reads that had haplotypes phased by at least five heterozygous SNPs were subjected to haplotype inference. The two most frequently observed haplotypes were considered parental haplotypes, whereas other haplotypes were recombinants. These haplotypes are summarized in Table 2 and are listed in the Additional file 1.

An example of haplotype inference is presented here to demonstrate how we inferred haplotypes from the 
PCR-free libraries that we constructed for the heterokaryon $(N \times N)$. The screenshot of Integrative Genomics Viewer (IGV) (Robinson et al. 2011) in Fig. 3 shows an alignment of 32 reads at scaffold 278 of the filtered heterokaryon, where 14 reads of one parental haplotype, 14 reads of the other parental haplotype, and two reads of two recombinant haplotypes have been aligned to the reference (indicated by a black arrow). The five heterozygous SNPs at positions 51,054, 51,057, 51,063, 51,069, and 51,071 are framed in black rectangles. Five incomplete reads are crossed out in black lines.

\section{Reverse transcription PCR (RT-PCR) and real-time quantitative PCR (RT-qPCR)}

Total RNA was isolated from a mycelial sample and a gill sample using TRIzol (Invitrogen Inc.) following the manufacturer's protocol. cDNA synthesis was performed using the First-Strand cDNA Synthesis Kit (Roche Diagnostics $\mathrm{GmbH}$ ) and anchored-oligo(dT)18 primers. RT-qPCR reactions were performed using FastStart Universal SYBR Green Master (Roche Diagnostics $\mathrm{GmbH}$ ). Translation elongation factor 1 alpha $(T E F 1 \alpha)$ was used as the internal normalization control with the primer pair GGTGTCAGGCAGCTCATCGT/ CGGTCCTCACTCCACTTGGT. PCR was performed on the QuantStudio 12K Flex ABI 7500 real-time PCR system in 8-tube strips. The exon-spanning primer pairs used for RT-qPCR analyses of SPO11, DMC1, MSH4, and $M L H 1$ are: CCAGCCACGAAACGAGACAT/ GCTCAAGAGTGGCAGCGATAT, AAATATTCTCTACGCCCGTGCAT/AAGTCCTTGTCCTCGGCAAA, G C G C C T T G C GA A G AT A G A G A / C G A T T G C GATGGGCCTTA, and TCTGCACTGAAAGAGCTGGTAGA/GGTCCGATTTGCGTATTCCA, respectively. The RT-qPCR reaction was performed in triplicate for each sample. Specificity of the amplifications and $\mathrm{Ct}$ values were analyzed using ABI PRISM dissociation curve analysis software.

\section{Results \\ Pairing tests}

The mating system of Termitomyces mushrooms has not been verified by pairing studies previously, being inferred heterothallic only in a study of the Termitomyces symbiont of Macrotermes natalensis from South Africa (de Fine Licht et al. 2005). We set out to pair 20 homokaryons (Table 1), which were obtained from the fruiting body $T 0984$ produced by a Termitomyces symbiont of $O$. formosanus in Taiwan. The molecular markers that we used had two haplotypes (alleles) at each of the two gene loci, mitochondrial intermediate peptidase $(M I P)$, which is closely linked to mating type locus $A$ in other studied mushrooms (James et al. 2004), and pheromone receptor $\left({ }^{* *} R C B\right)$, which is a region within mating type locus $B$ in other mushrooms (Aimi et al. 2005; Brown and Casselton 2001). Successful matings would render both haplotypes of $M I P$, denoted as $A_{1}$ and $A_{2}$, and both of $R C B$, denoted as $B_{1}$ and $B_{2}$, coexisting within a resulting heterokaryon. Cloning and sequencing amplicons of the two loci from the resulting heterokaryons confirmed that the two original haplotypes had come together in a heterokaryon as we expected from successful matings (Table 1). In other basidiomycetes, mating behavior dictated by two loci is considered tetrapolar heterothallism, where compatibility between paired homokaryons requires different haplotypes at each locus, whereas incompatibility occurs when only one or both of the two loci has the same haplotype (Brown and Casselton 2001; Raper 1966). Interestingly, pairings between homokaryons of the Termitomyces symbiont that were heterozygous at either $M I P$ only $\left(A_{1} B_{2} \times A_{2} B_{2}\right)$ or $R C B$ only $\left(A_{2} B_{2} \times A_{2} B_{1}\right)$ also resulted in heterokaryons with a normal mycelial growth,

Table 2 Recombinants in the homokaryons and heterokaryon

\begin{tabular}{|c|c|c|c|c|c|c|c|c|}
\hline & \multicolumn{2}{|l|}{ BSO5 } & \multicolumn{2}{|l|}{ BS17 } & \multicolumn{2}{|c|}{$B S 05 \times B S 17^{a}$} & \multicolumn{2}{|c|}{ Filtered $B S 05 \times B S 17^{a}$} \\
\hline & $\begin{array}{l}\text { Number } \\
\text { of reads }\end{array}$ & $\begin{array}{l}\text { Percentage } \\
(\%)\end{array}$ & $\begin{array}{l}\text { Number } \\
\text { of reads }\end{array}$ & $\begin{array}{l}\text { Percentage } \\
(\%)\end{array}$ & $\begin{array}{l}\text { Number } \\
\text { of reads }\end{array}$ & $\begin{array}{l}\text { Percentage } \\
(\%)\end{array}$ & $\begin{array}{l}\text { Number } \\
\text { of reads }\end{array}$ & $\begin{array}{l}\text { Percentage } \\
(\%)\end{array}$ \\
\hline $\begin{array}{l}\text { Non-recom- } \\
\text { binants ( } 2 \\
\text { haplotype) }\end{array}$ & $1,832,757$ & 80.28 & 1213,986 & 80.71 & 1450,156 & 81.41 & 401,623 & 94.96 \\
\hline $\begin{array}{l}\text { Recombinants } \\
\text { (30 haplo- } \\
\text { types) }\end{array}$ & 450,166 & 19.72 & 290,056 & 19.29 & 331,170 & 18.59 & 21,336 & 5.04 \\
\hline Total & 2282,923 & 100 & 1504,042 & 100 & 1781,326 & 100 & 422,959 & 100 \\
\hline
\end{tabular}

The table is a summary for haplotypes phased by at least 5 heterozygous SNPs within a read. The $32\left(=2^{5}\right)$ haplotypes, i.e., two non-recombinants and 30 recombinants, were inferred from every 5 heterozygous SNPs on the same reads

a The heterokaryon $B S 05 \times B S 17$ resulted from a mating between the two homokaryons $B S 05$ and $B S 17$. The filtered $B S 05 \times B S 17$ was obtained by excluding those recombinant haplotypes of $B S 05 \times B S 17$ that were shared by BS05 or BS17 in the haplotype inference (see "Methods" for detail) 


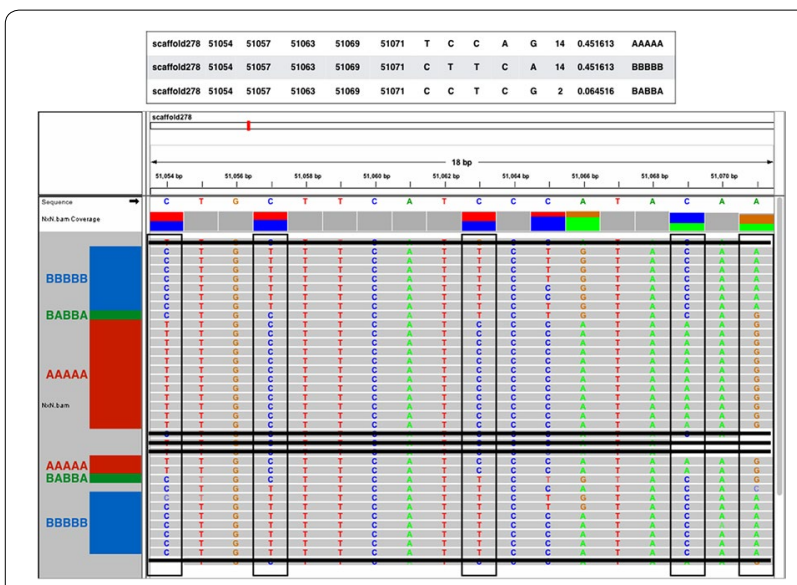

Fig. 3 An IGV screenshot showing inference of somatic meiotic-like recombination at scaffold 278

suggesting that self-incompatible mating is not strictly followed by or even lacked in the Termitomyces symbiont.

\section{Nuclear behavior revealed by cytological studies}

Curiously, cytological studies on heterokaryons resulting from successful pairings indicated that meiotic-like nuclear behavior occurred somatically in Termitomyces. Nuclei in a mycelium stained with HCl-Giemsa or DAPI were shown to be in a dikaryotic or trikaryotic arrangement in a newly formed hyphal tip cell (Fig. $4 a-h)$. Nuclei in the cell fused into a single nucleus before dividing into four and six in the dikaryotic and trikaryotic cells, respectively. A septum was then formed to bisect the divided nuclei, resulting in two or three nuclei per cell depending on the nuclear number of their parent cells. The nuclear region distributed with nuclear ribosomal RNA genes (rDNA), which are organized in tandem arrays of multiple copies, was probed by fluorescence in situ hybridization (FISH) (Fig. 4m-x). A chromosome set had one FISH signal only as demonstrated in uninucleate basidiospores (Fig. 4m). Multiple FISH signals were frequently observed in close association within a nucleus, suggesting that pairing of homologous chromosomes indeed occurred (Fig. $4 n-q, t$ ). While single FISH signal was normally detected in postmeiotic nuclei at hyphal tips (Fig. 4v), nuclei with two FISH signals (Fig. 4x) or more were occasionally found. The same nuclear behavior was also observed in the culture isolated from stipe tissue of the fruiting body T0984 $(F B)$ and the cultures reisolated from termite colonies inoculated with $F B$.

Cytological studies were also extended to homokaryons derived from single basidiospores, which were uninucleate but germinated into mycelia each containing both dikaryotic and trikaryotic cells. Interestingly, the hyphal cells divided in exactly the same fashion as those of heterokaryons. The sexual process revealed in the homokaryons is similar to the same-sex mating reported from the human pathogenic fungus Cryptococcus neoformans (Lin et al. 2005).

Conidia are commonly perceived as asexual spores of fungi, but in the Termitomyces symbiont, regardless of whether conidia were produced from heterokaryons or homokaryons, their nuclei, two or three per conidium, underwent karyogamy and a meiotic-like process as those of active hyphal cells (Fig. 4i, k). Termitomyces conidia, unlike those of other fungi which serve as clonally propagating and dispersal agents, are produced within nodules at fungus gardens within sequestered termite colonies. Nodules, which contain thin-walled, inflated cells and hyphae in addition to conidia, are consumed by termite workers as an important part of the termite diets (Batra and Batra 1979). Conidia appear to be the only fungal elements surviving the alimentary tracts. Fecal balls excreted and deposited onto fungus gardens by worker termites thus mainly contain conidia and ingested foraged plant debris. Conidia germinate within hours after fecal ball deposition to resume the fungal growth at fungus gardens.

\section{Occurrence of genetic recombination at somatic stage}

Recombination of homologous nuclear DNA does not normally occur within a lone heterokaryon in other basidiomycetes. To detect if genetic recombination occurred during vegetative growth in the Termitomyces symbiont, we performed whole-genome sequencing of two homokaryons BSO5 and BS17 and a heterokaryon BSO5 × BS17, which resulted from mating of the two homokaryons, with an Illumina HiSeq 2500 platform. The sequencing libraries were deliberately constructed without involving PCR amplifications to avoid PCR-mediated recombination (see Additional file 2: Text S1), and obtained reads were aligned to the reference genome Termitomyces sp. J132 (Poulsen et al. 2014). To identify recombinants among the reads, we reconstructed haplotypes by phasing heterozygous SNPs in close proximity. Estimated recombinants from $B S 05$, BS17, and BSO5 × BS17 were 19.72, 19.29, and 18.59\%, respectively (see Table 2; Additional file 1). The recombinants found in the homokaryons possibly resulted from long-term accumulation of gene duplication and/or repetitive sequences within a genome, which is known to be rich in fungal genomes (Raffaele and Kamoun 2012), or from chromosomal rearrangements (Heitman et al. 2013; Perkins 1997) (see Possible account for recombination events occurring in the homokaryon of "Discussion"). We thus excluded the recombinant haplotypes from alignments of BSO5 $\times$ BS17 that were shared with BSO5 or BS17. Estimated recombinants in the resulting alignments of the total haplotypes were $5.04 \%$ (Table 2). Genetic recombination occurred genome-wide, with a slight, less than 
Fig. 4 Nuclei at various stages of the Termitomyces symbiont. $\mathbf{a}-\mathbf{h}$ Vegetative hyphal tips. Nuclei in $\mathbf{a}, \mathbf{c}, \mathbf{e}, \mathbf{g}$, and $\mathbf{i}$ were stained with $\mathrm{HCl}$-Giemsa, whereas those in $\mathbf{b}, \mathbf{d}, \mathbf{f}$, and $\mathbf{h}$ were with DAPI. a, b A fused nucleus in the terminal cell. Nuclei of the penultimate cell in b are about to fuse. c, $\mathbf{d}$ Elongated nuclei at the stage resembling Meiosis I. e, f Nuclei resulting from a binucleate parent cell right after the stage resembling Meiosis II. Septum (arrowhead) is forming to bisect the four nuclei in $\mathbf{e .} \mathbf{g}, \mathbf{h}$ Nuclei resulting from a trinucleate parent cell right after the stage resembling meiosis II. i Conidiophore attached with developing conidia, each of which has a fused nucleus or two nuclei ready to fuse. $\mathbf{j}, \mathbf{k}$ Conidia. Those in $\mathbf{j}$ are binucleate, whereas those in $\mathbf{k}$ are either uninucleate or quadrinucleate (arrowhead). I Uninucleate basidiospores. $\mathbf{m}-\mathbf{x}$ Nuclei labelled with red FISH probes at ITS1-5.8S rDNA-ITS2 region and counterstained with DAPI to render the nuclei blue. $\mathbf{m}$ Haploid nucleus of a basidiospore showing a FISH signal. n-r Nuclei at various stages of the meiotic-like process released from hyphae. $\mathbf{n}$ Nucleus at prophase showing FISH signals on four stringy chromatids attached to a nucleolus (the dark region pointed by an arrowhead). o Nucleus at prophase. p Nucleus at early metaphase showing FISH signals on four condensed chromatids attached to a nucleolus (the dark region pointed by an arrow). q Nucleus at metaphase, with chromosomes shown as condensed blue spots. $\mathbf{r}$ Nucleus at anaphase. $\mathbf{s}-\mathbf{x}$ Nuclei at vegetative hyphal tips, which appear hazy owing to cell wall being partially digested by enzymes. s Two haploid nuclei before karyogamy. $\mathbf{t}$ Fused nucleus at prophase. $\mathbf{u}$ Two nuclei at a stage resembling anaphase of meiosis II. $\mathbf{v}$ Four nuclei after a meiotic-like division. $\mathbf{w}$ Three haploid nuclei before karyogamy. $\mathbf{x}$ Aberrant hyphal tip showing five postmeiotic nuclei with two (arrowheads) still active in division. Scale bars in $\mathbf{a}-\mathbf{m}$, $\mathbf{s}-\mathbf{x}=5 \mu \mathrm{m}$, and $\mathbf{n}-\mathbf{r}=2.5 \mu \mathrm{m}$

twofold enrichment and depletion at genic and intergenic regions, respectively (Fig. 5).

\section{Expression of meiosis-specific genes}

To further test if the genetic recombination occurring in mycelia is meiotic-like, four meiosis-specific genes, including SPO11, DMC1, MSH4, and MLH1, which are not normally expressed at somatic stage in other organisms (Schlecht and Primig 2003), were selected for examination in a mycelial sample. Fruiting bodies of a typical mushroom species have thin, vertically oriented, platelike gills beneath the cap, which are entirely overlain with crowdedly arranged basidia. Meiosis is commonly considered to be restricted to basidia (Anderson and Kohn 2007; Kües 2000). A gill sample was thus included and compared with the mycelial sample for expression of the four meiosis-specific genes. RNA transcripts of the four genes from the two samples were first detected by reverse transcription PCR (RT-PCR) (Fig. 6a), and the confirmed RNA transcripts were cloned and used for designing primers for real-time quantitative PCR (RTqPCR) analyses. Results of RT-qPCR showed that all four meiotic genes were expressed in the mycelial sample (Fig. 6b). Although higher expression of these four

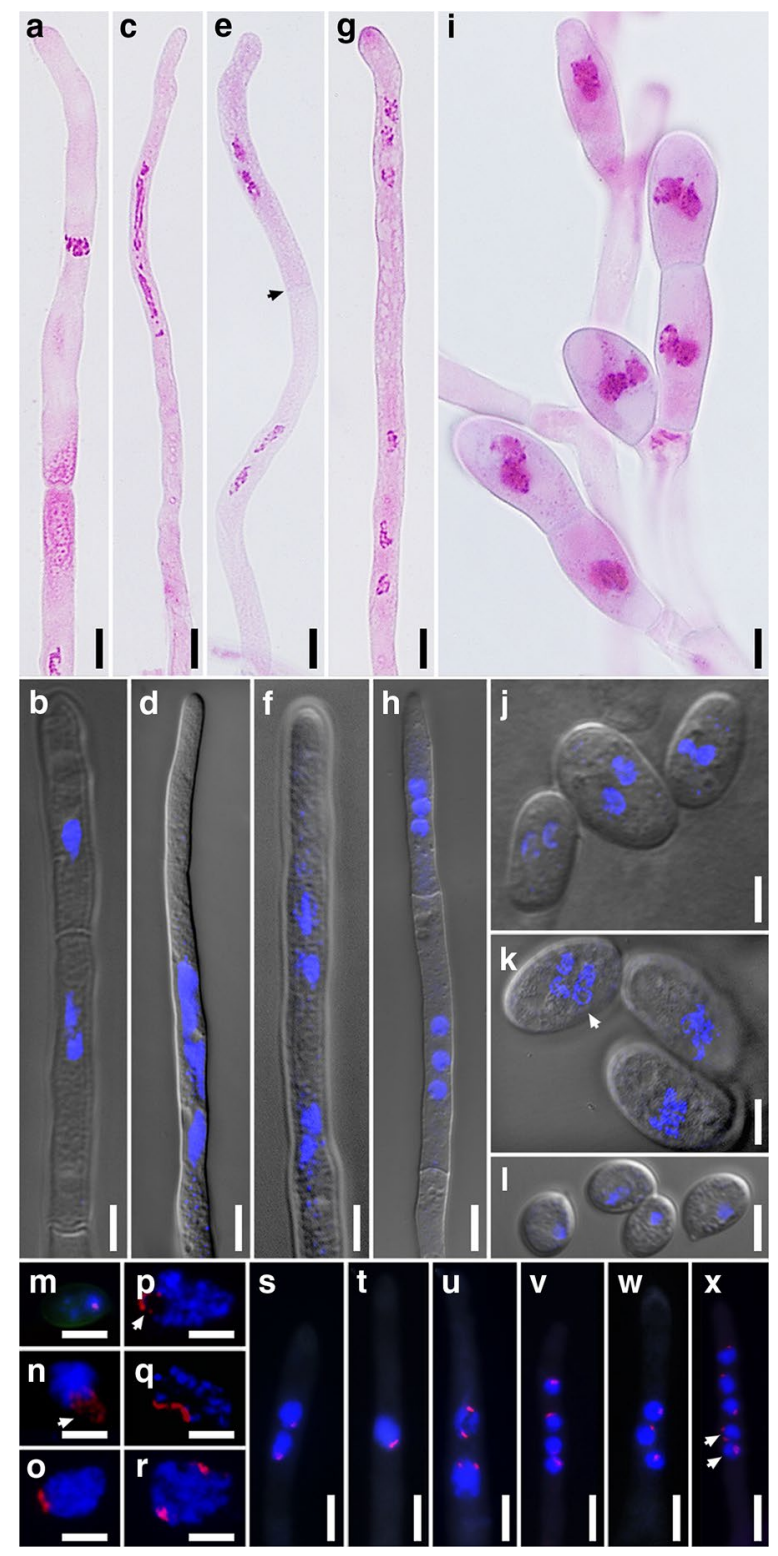

meiotic genes was detected in the gill sample, successful amplification and $<30$ threshold cycle value $(\mathrm{Ct})$ in the mycelial sample confirmed their expression in mycelia. The difference in expression levels between mycelia and gills may be due to cells (i.e., basidia) undergoing meiosis in the gills being higher in percentage than those (i.e., only hyphal tips) in the mycelia. While gene expressions do not always correspond to gene functions, it should be noted that meiotic genes, especially genes involving recombination, are normally under tight expression control to prevent deleterious consequences of genomic instability. 


\section{Discussion}

\section{Sexual process in the Termitomyces mushroom}

The novel life cycle that we present here for the Termitomyces symbiont represents a highly interesting case in evolution of sex, where the fungus maximizes the sexual process by vigorously reshuffling its genetic makeup in a meiotic-like fashion during each somatic cell division and conidial production irrespective of whether or not mating has occurred. It is to be found out whether or not this process continues in tissue of the fruiting body and terminates at basidia. Basidia are the only sites of sexual activity known in other basidiomycetes, where sex (karyogamy and meiosis) and reproduction (basidiospore formation) are tightly coupled (Aanen and Hoekstra 2007). Sex of the Termitomyces symbiont prevails at somatic stage and looks as if uncoupled with reproduction process except for the brief duration of basidiospore production. Nonetheless, growth of vegetative hyphae in fungus gardens can readily be diverted to conidial production after colonization of fecal balls, and conidia are sexual rather than asexual. The coupling between sex and reproduction in the Termitomyces symbiont is not tight, but more frequent than what it appears by way of conidial production.

Sexual processes have been widely regarded as being costlier than asexual ones (Barton and Charlesworth 1998; Bell 1982; Burt 2000; Maynard Smith 1971; Otto 2009; Williams 1975). The "cost of meiosis" or "cost of sex" remains a puzzling question in evolutionary biology despite the fact that sex in general has been accepted by many for generating genetically variable progeny, upon which natural selection can act to accelerate evolution for adaption and for eliminating deleterious mutations. Nests of fungus-growing termites are sequestered environments, where Termitomyces fungi are essentially sheltered from outside (Mueller et al. 2005). The nests are generally considered homeostatic with fine-tuned microclimates, which are characterized by high moistures, elevated temperatures ca. $30{ }^{\circ} \mathrm{C}$, and high $\mathrm{CO}_{2}$ concentrations, in favor of Termitomyces growth (Korb 2003; Thomas 1987; Turner 2004) but stressful to other microbes, which are relatively low in diversities (Cooke and Whipps 1987). If the nest environments are in homeostasis and if sex is for adaptation, what could be the driving force propelling the Termitomyces symbiont to keep sexuality over asexuality? Mycelia and nodules of the symbiont are frequently and constantly under termite consumption, which undoubtedly imposes an immediate, continuous pressure upon the symbiont, whose cellular components, notably nuclei and DNA-containing organelles, will be digested if they fail to enter indigestible conidia. Conidia are thus like Noah's ark in that only a certain number or percentage of cellular components can gain entrance into them to ultimately survive the termite gut passage. Strong competition in entering conidia among rivalling cellular components may exist and exert a direct driving force upon the symbiont to produce conidia high in genetic variability as opposed to clonality in order to adapt to the next round of termite consumption.

\section{Choice of using FISH in detecting ploidy level of nuclei at hyphal tips}

Flow cytometry has been employed extensively in detecting ploidy level of nuclei. However, using this method to study nuclei located at hyphal tips is extremely difficult, if not infeasible, unless hyphal tip cells could be excised and collected selectively to pass through the narrowing channel of a flow cytometer. FISH with rDNA (ITS1-5.8S rDNA-ITS2) as the probe DNA, on the other hand, is a useful method for visualizing and determining ploidy level of nuclei at hyphal tips, where the meiotic-like divisions occur. The images shown in Fig. $4 \mathrm{~m}-\mathrm{x}$ are representatives at various nuclear stages observed during our FISH experiments. For example, the nucleus at Fig. $4 n$ was unmistakably identified as a diploid at prophase because it had four FISH signals on four stringy chromatins, which means a pair of $45 \mathrm{~S}$ rDNA in a diploid genome undergoing a duplication process at this stage. Nuclei in Fig. $4 \mathrm{v}-\mathrm{x}$ were haploid resulting from meioticlike division because there was only one FISH signal detected in each of the nuclei.

\section{Possible account for recombination events occurring in the homokaryon}

Fungal genomes are highly dynamic, rich in chromosomal rearrangement (Heitman et al. 2013; Perkins 1997). In the Termitomyces symbiont, recombinants were detected not only in the heterokaryon $B S O 5 \times B S 17$ but

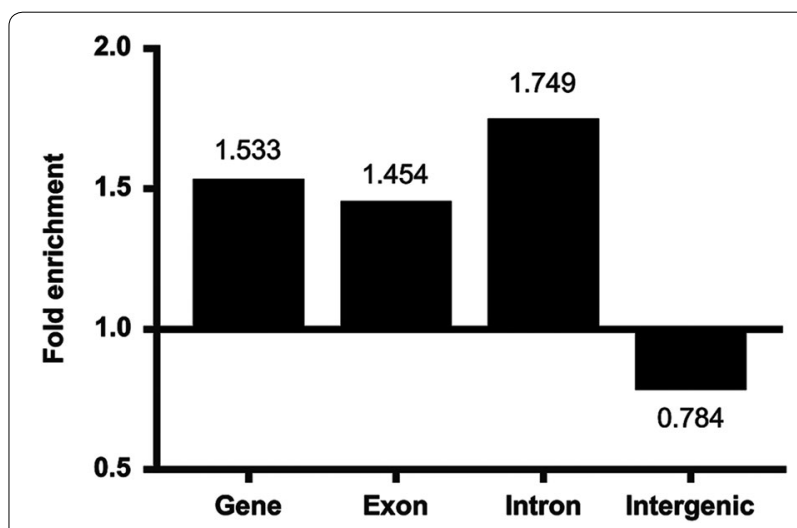

Fig. 5 Distribution of recombinants in different genomic regions. The fold enrichment was calculated by comparing the percentage of the recombinants in a specific genomic region against the percentage of the region in the genome 
also in the homokaryon BS05. We excluded the possibility that the recombinants in the homokaryon sample originated from contaminants by checking reads at four protein-coding gene loci listed in Additional file 2: Table S2, where only one parental haplotype was detected at each locus.

To explain how recombinants could have arisen in the homokaryon but not in the heterokaryon and vice versa, we use a schematic diagram (Fig. 7) to demonstrate that one unique recombination was detected in each of the heterokaryon and the homokaryon and that one recombination was shared by both. At step 1, two parental haploid nuclei, P1 and P2, fused to form a diploid nucleus $(P 1 \times P 2)$, with a reciprocal recombination occurring at each of the two chromosome sets, i.e., one between loci c and $\mathrm{d}$, and the other between loci y and z. At step 2, four daughter nuclei, D1, D2, D3, and D4, were produced after the meiotic-like process. At step 3, nuclei D1 and D2 fused, and the chromosome arm carrying alleles $\mathrm{c}_{1}, \mathrm{~d}_{2}, \mathrm{e}_{2}, \mathrm{f}_{2}$ was translocated onto the chromosome carrying alleles $\mathrm{w}_{1}, \mathrm{x}_{1}$, $\mathrm{y}_{1}$, and $\mathrm{z}_{1}$. Among the meiotic products, nuclei N1 and N2 require further attention, because $\mathrm{N} 1$ acquired the chromosome arm that was lost in N2. At step 4, N1', a nucleus derived from N1, was encapsulated within a basidiospore, which developed into homokaryon I. Within homokaryon I, F1 was developed from $\mathrm{N} 1^{\prime}$ through the intermediate state $\mathrm{N} 1^{\prime}-\mathrm{F} 1$, where a non-homologous recombination occurred between loci $\mathrm{d}$ and e of the two chromosomes. When homokaryon I mated with homokaryon II, only nucleus $\mathrm{N1}^{\prime \prime}$, which derived from $\mathrm{N1}^{\prime}$, migrated to the heterokaryon (step 5), where it paired with nucleus D3", which derived from nucleus D3' of homokaryon II (step 7). Nucleus D3' had its origin from nucleus D3 (step 6).

Recombination sites at the heterokaryon that resulted from plasmogamy between homokaryon I and homokaryon II were detected between loci $\mathrm{c}$ and $\mathrm{d}$ and between loci $\mathrm{y}$ and $\mathrm{z}$, while those at homokaryon I were between loci $\mathrm{c}$ and $\mathrm{d}$ and between loci $\mathrm{d}$ and e. In the heterokaryon, the recombination site between loci $\mathrm{y}$ and $\mathrm{z}$ is considered reliable but the site between loci $\mathrm{c}$ and $\mathrm{d}$ was filtered out because it was shared by homokaryon I and the heterokaryon. The recombination site between loci $\mathrm{d}$ and e was unique to homokaryon I, becoming possible after the chromosome translocation event at step 3.

\section{Mating system of the Termitomyces symbiont not dictated by heterogenic compatibility}

Two basic mating systems are known in mushrooms: homothallic (self-fertile) and heterothallic (self-sterile). Only $10 \%$ of the mushroom species have a homothallic mating system and can complete a life cycle without mating. The others have a heterothallic mating system and require fusion between mycelia with different

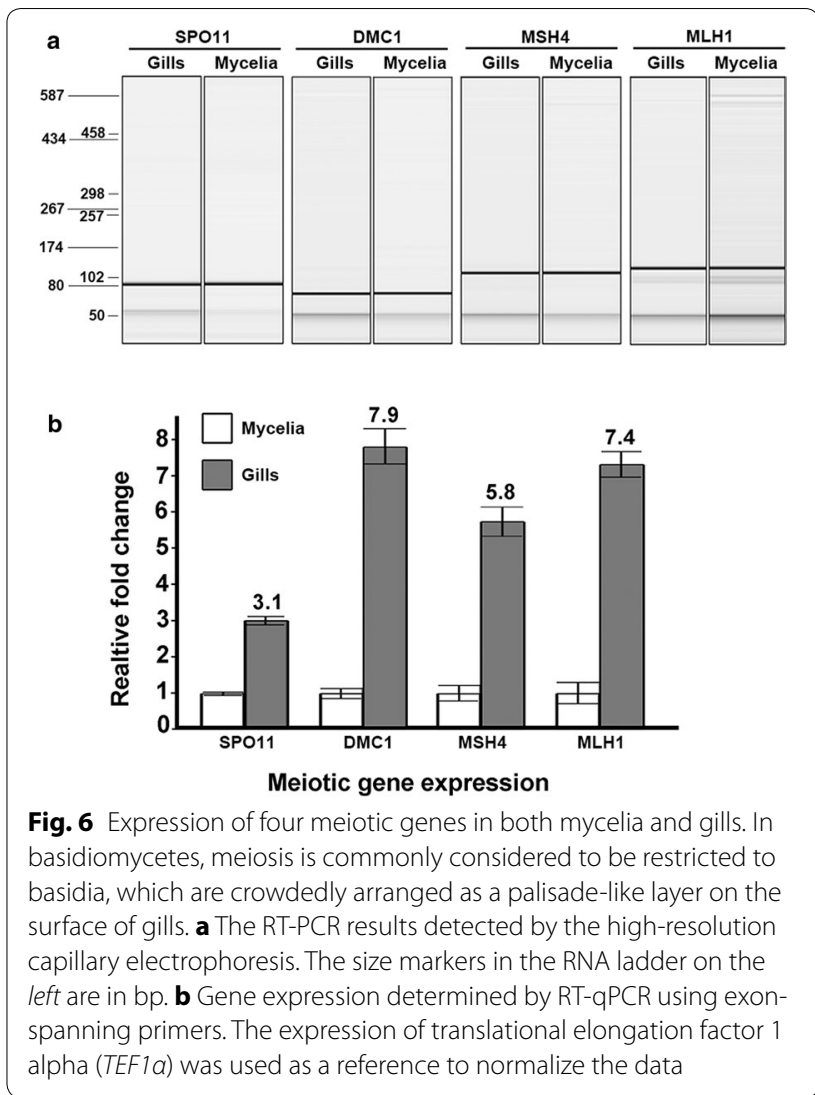

mating types, which, depending on mushroom species, are determined by either one locus (bipolar heterothallism) or two loci (tetrapolar heterothallism) (Whitehouse 1949). Compatibility can only be achieved when the two mates have different alleles at each locus, i.e., heterogenic compatibility (Esser 2006).

$M I P$ and $R C B$, as initially planned, were used as markers to suggest the mating system of Termitomyces. These markers were assumed to be associated with the mating type loci $A$ and $B$ (Aimi et al. 2005; James et al. 2004), with the mating system of the Termitomyces symbiont being assumed to be tetrapolar heterothallism. This assumption was thus made simply because there happened to be exactly two haplotypes for each of the two marker loci among the 45 homokaryons that we obtained from T0984. While capability of mating between some homokaryons has been verified in our study, it remains uncertain if mating is indeed a necessity for the Termitomyces symbiont to complete a life cycle. Definite answers will be possible only after a reliable fruiting system becomes available. If mating is eventually proven to be required, only heterokaryons will produce fruiting bodies, while homokaryons remain fruitless. Otherwise, both homokaryons and heterokaryons can fruit. 


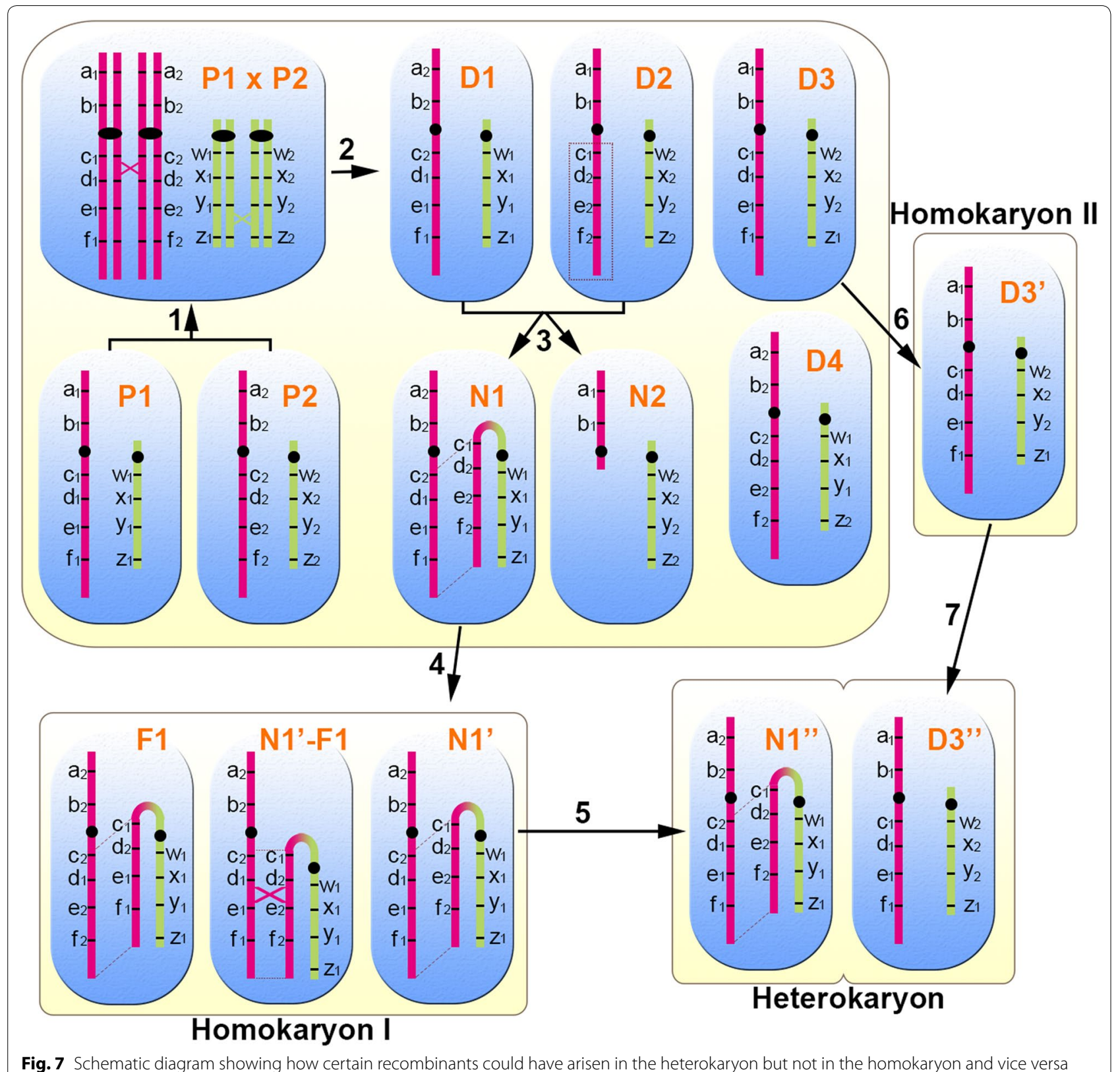

The only previous study concerning the mating system of the Termitomyces symbiont of Macrotermes natalensis from South Africa (de Fine Licht et al. 2005) suggests that the fungal symbiont is heterothallic, requiring two compatible mating types to complete a life cycle. It is because two haplotypes of internal transcribed spacers (ITS) of nuclear ribosomal DNA were detected in cultures obtained from fungus gardens but only one of the two haplotypes was in each of the five single basidiospore cultures that they obtained. Despite the fact that their results agree with data showing that Termitomyces cultures isolated from termite colonies are heterokaryotic (Aanen et al. 2009), uncertainty remains because extensive pairings between single basidiospore isolates (homokaryons) were not conducted and, moreover, a reliable system for mushroom fruiting was not developed.

\section{Somatic genetic recombination known or suspected to exist in other basidiomycetes}

In many basidiomycetes, somatic genetic recombination does not normally occur but can be triggered in a heterokaryon upon its confrontation with a homokaryon (the Buller phenomenon) during an incompatible heterokaryon-homokaryon mating, $\left(A_{1} B_{2}+A_{2} B_{1}\right) \times A_{1} B_{1}$. The 
resulting recombinant $A_{2} B_{2}$ nuclei then migrate from the heterokaryon into the homokaryon to pair with $A_{1} B_{1}$ nuclei (Anderson and Kohn 2007; Raper 1966). In addition to the Buller phenomenon, somatic genetic recombination in basidiomycetes is known to occur in three different ways: a meiotic-like process, parasexuality, and internuclear specific factor transfer (Anderson and Kohn 2007). A meiotic-like process is more likely for the Termitomyces symbiont, because specific factor transfer is highly unlikely to be genome-wide, and parasexuality occurs in extremely low frequencies.

We suspect that the novel life cycle that we describe in this study can also be found in other Termitomyces species and in basidiomycetes of other genera. Intragenic recombination has been reported from EF1a and other DNA regions among Termitomyces isolates from 31 colonies of Macrotermes natalensis in South Africa, which apparently belonged to a breeding population but curiously lacked apparent mushroom fruiting (de Fine Licht et al. 2006). Matings between compatible haploid monokaryons in two honey mushrooms, Armillaria gallica (Peabody et al. 2005) and Armillaria tabescens (Grillo et al. 2000), resulted in a haploid dikaryon and subsequently a persistent diploid monokaryon by karyogamy. Tissue of fruiting bodies, however, contained haploid dikaryotic cells and was shown to be genetically mosaic, implying somatic genetic recombination during haploidization. Somatic genetic recombination were occasionally detected within dikaryons of Schizophyllum commune (Frankel 1979; Parag 1962), and episodic somatic recombination was monitored and detected in culture of dikaryons for 18 months (Clark and Anderson 2004).

\section{Conclusion}

Despite the fact that the sexual process that we found in the Termitomyces mycelia is much like meiosis, we still have reservation in considering it typical meiosis mainly due to: (1) karyogamy within a hyphal tip cell involving fusion of two nuclei in some cases and three nuclei in other cases, and (2) further confirmation, in addition to our cytological studies, needed on ploidy changes, especially in those cases where three nuclei are involved. Somatic meiotic-like recombination in the Termitomyces symbiont is seemingly analogous with VDJ recombination known in human immune system in being able to recombine genetic material somatically. Further studies are needed to investigate whether or not meiotic-like recombination also confers to the Termitomyces symbiont similar vigilance and agility to the human immune system in quickly responding to invaders. Our study emphasizes the necessity of further understanding the genetics of Termitomyces symbionts, which are organisms centered on the stage of termite agriculture, in order to learn what and how meiotic-like recombination affects the termite agroecosystem. Our findings are likely to generate a profound influence on how we perceive termite agriculture as well as the endurance of Termitomyces monoculture with termites over tens of millions of years.

\section{Additional files}

Additional file 1. Termitomyces_haplotypes.

Additional file 2. Additional information.

\section{Authors' contributions}

$\mathrm{HMH}, \mathrm{MCC}, \mathrm{ANS}, \mathrm{CRL}, \mathrm{MJF}, \mathrm{BCHC}$, and YMJ collected data; HMH, MCC, and YMJ analyzed data; YMJ wrote the manuscript; WNC collected the Termitomyces fruiting body; CYL, CCH, and JCC commented on the manuscript; MCC, CYL, $\mathrm{CCH}$, and YMJ were project leaders. All authors read and approved the final manuscript.

\section{Author details}

${ }^{1}$ Institute of Plant and Microbial Biology, Academia Sinica, Taipei 11529, Taiwan. ${ }^{2}$ Graduate Institute of Biotechnology, National Changhua University of Education, Changhua 50074, Taiwan. ${ }^{3}$ Department of Life Sciences, National Chung Hsing University, Taichung 40227, Taiwan. ${ }^{4}$ Department of Natural Resources and Environmental Studies, National Dong Hwa University, Hualien 97401, Taiwan. ${ }^{5}$ National Museum of Natural Science, Taichung 40453, Taiwan. ${ }^{6}$ Yourgene Bioscience, New Taipei 23863, Taiwan.

\section{Acknowledgements}

We thank Jack D. Rogers, Washington State University, USA, for reading the manuscript and Archana Allishe, Academia Sinica, for helping the submission of SRA data to NCBI.

\section{Competing interests}

The authors declare that they have no competing interests.

Availability of data and materials

The datasets supporting the conclusions of this article are available at NCBI as Study SRP073090 in https://www.ncbi.nlm.nih.gov.

Consent for publication

Not applicable.

Ethics approval and consent to participate

Not applicable.

\section{Funding}

This work was supported by Ministry of Science and Technology (formerly National Science Council, Grant Number NSC 99-2321-B-001-030-MY3) of Taiwan, by Summit Project, Academia Sinica, and by Innovative Translational Agricultural Research, Academia Sinica to Y-MJ.

\section{Publisher's Note}

Springer Nature remains neutral with regard to jurisdictional claims in published maps and institutional affiliations.

Received: 7 April 2017 Accepted: 19 August 2017

Published online: 19 September 2017

\author{
References \\ Aanen DK, Eggleton P (2005) Fungus-growing termites originated in African \\ rain forest. Curr Biol 15:851-855
}


Aanen DK, Hoekstra RF (2007) Why sex is good: on fungi and beyond. In: Heitman J, Kronstad JW, Taylor JW, Casselton LA (eds) Sex in fungi: molecular determination and evolutionary implications. ASM Press, Washington, DC, pp 527-534

Aanen DK, de Fine Licht HH, Debets AJ, Kerstes NA, Hoekstra RF, Boomsma JJ (2009) High symbiont relatedness stabilizes mutualistic cooperation in fungus-growing termites. Science 326:1103-1106

Aimi T, Yoshida R, Ishikawa M, Bao D, Kitamoto Y (2005) Identification and linkage mapping of the genes for the putative homeodomain protein (hox 1) and the putative pheromone receptor protein homologue (rcb1) in a bipolar basidiomycete, Pholiota nameko. Curr Genet 48:184-194

Anderson JB, Kohn LM (2007) Dikaryons, diploids, and evolution. In: Heitman J, Kronstad JW, Taylor JW, Casselton LA (eds) Sex in fungi: molecular determination and evolutionary implications. ASM Press, Washington, DC, pp 333-348

Barton NH, Charlesworth B (1998) Why sex and recombination? Science 281:1986-1990

Batra LR, Batra SWT (1979) Termite-fungus mutualism. In: Batra LR (ed) Insectfungus symbiosis: nutrition, mutualism and commensalism. Montclair, Allanheld, Osmun \& Co, pp 117-163

Bell G (1982) The masterpiece of nature: the evolution and genetics of sexuality. University of California Press, Berkeley

Brown AJ, Casselton LA (2001) Mating in mushrooms: increasing the chances but prolonging the affair. Trends Genet 17:393-400

Burt A (2000) Perspective: sex, recombination, and the efficacy of selectionwas Weismann right? Evolution 54:337-351

Chung MC, Lee Yl, Cheng YY, Chou YJ, Lu CF (2008) Chromosomal polymorphism of ribosomal genes in the genus Oryza. Theor Appl Genet 116:745-753

Clark TA, Anderson JB (2004) Dikaryons of the basidiomycete fungus Schizophyllum commune: evolution in long-term culture. Genetics 167:1663-1675

Cooke RC, Whipps JM (1987) Saprotrophy, stress and symbiosis. In: Rayner ADM, Brasier CM, Moore D (eds) Evolutionary biology of the fungi. Cambridge University Press, Cambridge, pp 137-148

Cook-Patton SC, McArt SH, Parachnowitsch AL, Thaler JS, Agrawal AA (2011) A direct comparison of the consequences of plant genotypic and species diversity on communities and ecosystem function. Ecology 92:915-923

de Fine Licht HH, Andersen A, Aanen DK (2005) Termitomyces sp. associated with the termite Macrotermes natalensis has a heterothallic mating system and multinucleate cells. Mycol Res 109:314-318

de Fine Licht HH, Boomsma JJ, Aanen DK (2006) Presumptive horizontal symbiont transmission in the fungus-growing termite Macrotermes natalensis. Mol Ecol 15:3131-3138

Esser K (2006) Heterogenic incompatibility in fungi. In: Kües U, Fischer R (eds) The mycota a comprehensive treatise on fungi as experimental systems for basic and applied research I growth, differentiation and sexuality, 2nd edn. Springer, Berlin, pp 141-165

Frankel C (1979) Meiotic-like recombination in vegetative dikaryons of Schizophyllum commune. Genetics 92:1121-1126

Grillo R, Korhonen K, Hantula J, Hietala AM (2000) Genetic evidence for somatic haploidization in developing fruit bodies of Armillaria tabescens. Fungal Genet Biol 30:135-145

Heitman J, Sun S, James TY (2013) Evolution of fungal sexual reproduction. Mycologia 105:1-27

James TY, Kües U, Rehner SA, Vilgalys R (2004) Evolution of the gene encoding mitochondrial intermediate peptidase and its cosegregation with the $\mathrm{A}$ mating-type locus of mushroom fungi. Fungal Genet Biol 41:381-390

Johnson RA (1981) Colony development and establishment of the fungus comb in Microtermes sp. nr usambaricus (Sjöstedt) (Isoptera: Macrotermitinae) from Nigeria. Insectes Sociaux 28:3-12

Johnson RA, Thomas RJ, Wood TG, Swift MJ (1981) The inoculation of the fungus comb in newly founded colonies of some species of the Macrotermitinae (Isoptera) from Nigeria. J Nat Hist 15:751-756

Katoh H, Miura T, Maekawa K, Shinzato N, Matsumoto T (2002) Genetic variation of symbiotic fungi cultivated by the macrotermitine termite Odontotermes formosanus (Isoptera: Termitidae) in the Ryukyu Archipelago. Mol Ecol 11:1565-1572
Knox-Davies PS, Dickson JG (1960) Cytology of Helminthosporium turcicum and its ascigerous stage, Trichometasphaeria turcica. Am J Bot 47:328-339

Korb J (2003) Thermoregulation and ventilation of termite mounds. Naturwissenschaften 90:212-219

Kües U (2000) Life history and developmental processes in the basidiomycete Coprinus cinereus. Microbiol Mol Biol Rev 64:316-353

Langmead B, Salzberg SL (2012) Fast gapped-read alignment with Bowtie 2. Nat Methods 9:357-359

Lin XR, Hull CM, Heitman J (2005) Sexual reproduction between partners of the same mating type in Cryptococcus neoformans. Nature 434:1017-1021

Martin M (2011) Cutadapt removes adapter sequences from high-throughput sequencing reads. EMBnet J 17:10-12

Maynard Smith J (1971) What use is sex. J Theor Biol 30:319-335

Mueller UG, Gerardo NM, Aanen DK, Six DL, Schultz TR (2005) The evolution of agriculture in insects. Annu Rev Ecol Evol Syst 36:563-595

Otto SP (2009) The evolutionary enigma of sex. Am Nat 174:S1-S14

Parag Y (1962) Studies on somatic recombination in dikaryons of Schizophyllum commune. Heredity 17:305-318

Peabody RB, Peabody DC, Tyrrell MG, Edenburn-MacQueen E, Howdy RP, Semelrath KM (2005) Haploid vegetative mycelia of Armillaria gallica show among-cell-line variation for growth and phenotypic plasticity. Mycologia 97:777-787

Perkins DD (1997) Chromosome rearrangements in Neurospora and other filamentous fungi. In: Hall J, Dunlap J, Friedmann T, Giannelli F (eds) Advances in Genetics, vol 36. Academic Press, San Diego, pp 239-398

Poulsen M, Hu HF, Li C, Chen ZS, Xu LH, Otani S, Nygaard S, Nobre T, Klaubauf S, Schindler PM et al (2014) Complementary symbiont contributions to plant decomposition in a fungus-farming termite. Proc Natl Acad Sci USA 111:14500-14505

Raffaele S, Kamoun S (2012) Genome evolution in filamentous plant pathogens: why bigger can be better. Nat Rev Microbiol 10:417-430

Raper JR (1966) Genetics of sexuality in higher fungi. Ronald Press Co., New York

Raudaskoski M, Kothe E (2010) Basidiomycete mating type genes and pheromone signaling. Eukaryot Cell 9:847-859

Roberts EM, Todd CN, Aanen DK, Nobre T, Hilbert-Wolf HL, O'Connor PM, Tapanila L, Mtelela C, Stevens NJ (2016) Oligocene termite nests with in situ fungus gardens from the Rukwa Rift Basin, Tanzania, support a Paleogene African origin for insect agriculture. PLoS ONE 11:e0156847

Robinson JT, Thorvaldsdottir H, Winckler W, Guttman M, Lander ES, Getz G, Mesirov JP (2011) Integrative genomics viewer. Nat Biotechnol 29:24-26

Sands WA (1960) The initiation of fungus comb construction in laboratory colonies of Ancistrotermes quineensis (Silvestri). Insectes Sociaux 7:251-263

Schlecht U, Primig M (2003) Mining meiosis and gametogenesis with DNA microarrays. Reproduction 125:447-456

Shinzato N, Muramatsu M, Watanabe Y, Matsui T (2005) Termite-regulated fungal monoculture in fungus combs of a macrotermitine termite Odontotermes formosanus. Zool Sci 22:917-922

Thomas RJ (1987) Factors affecting the distribution and activity of fungi in the nests of Macrotermitinae (Isoptera). Soil Biol Biochem 19:343-349

Turner JS (2004) Gaia, extended organisms, and emergent homeostasis. In: Schneider SH, Miller JR, Crist E, Boston PJ (eds) Scientists Debate Gaia: the next century. MIT Press, Cambridge, pp 57-71

Ward EWB, Ciurysek KW (1962) Somatic mitosis in Neurospora crassa. Am J Bot 49:393-399

White TJ, Bruns B, Lee S, Taylor J (1990) Amplification and direct sequencing of fungal ribosomal RNA genes for phylogenetics. In: Innis MA, Gelfand DH, Sninsky JJ, White TJ (eds) PCR protocols, a guide to methods and applications. Academic Press, San Diego, pp 315-322

Whitehouse HLK (1949) Multiple-allelomorph heterothallism in the fungi. New Phytol 48:212-244

Williams GC (1975) Sex and evolution. Princeton University Press, Princeton 